\title{
The Fluorescent Particle Atmospheric Tracer
}

\author{
Phimip A. Leighton, Wirliam A. Perkins, Stuart W. Grinnell and Francis X. Webster \\ Melronics Associates, Inc., Palo Allo, Calif.
}

(Manuscript received 18 November 1964, in revised form 24 February 1965)

\section{ABSTRACT}

\begin{abstract}
This paper describes the current status and discusses the validity of the fluorescent particle (FP) tracer technique. Properties of the material itself, the blower generator, membrane filter, drum impactor, and Rotorod samplers, and of counting techniques, are described. The inherent and operational errors involved are evaluated, and evidence on the atmospheric diffusion, fallout and impaction, and fluorescent stability of the particles is presented. It is concluded that in the present state of development of the technique the errors, in terms of $90 \%$ confidence intervals, are approximately $\pm 5-10 \%$ for source strength determination, $\pm 10-12 \%$ (if 300 particles are counted) for dosages determined by the Rotorod, and $\pm 17-20 \%$ for dosages determined by the membrane filter sampler. The effects of atypical diffusion on the validity of the method appear to be insignificant, and fluorescence losses may be controlled by proper selection of materials. For ground releases the losses by fallout and impaction may amount to from $1 \%$ to $10 \%$ during the first few miles of travel, depending on the rate of rise of the cloud and the nature of the ground cover. For larger travel distances, if the cloud height exceeds 100 meters the fallout loss should be below $2 \%$ per hour.
\end{abstract}

\section{Introduction}

Shortly after World War II the development of a tracer system for use in studies of airflow trajectories and the travel and diffusion of airborne materials was undertaken at Stanford University under contract with the U. S. Army Chemical Corps. The decision to use a fluorescent particulate in the $1-5 \mu$ size range, with assessment by counting individual particles, was made in 1946 (Grinnell et al.), the first field trial with this tracer was conducted in 1947 (Leighton $e t$ al.), the system was publicly described in 1951 (Perkins et al.), and an operational manual covering the technique as developed up to that time was published in 1955 (Leighton).

Since 1955 the technique has been improved, several fundamental questions on the validity of the method have been raised and answered, and its capabilities and limitations have been further investigated. Since 1955, also, the use of tracers has expanded and at least one other system has been proposed for general use (Robinson et al., 1959; Dumbauld, 1962). In view of these advances, it is considered timely to present this description of the current status of the fluorescent particle (FP) tracer technique, with emphasis on its limitations as well as on its capabilities.

\section{Requirements and choice of an atmospheric tracer}

The suitability of any material for use as an atmospheric tracer may be assessed in terms of its ability to meet a number of requirements. First, the material must possess a specific property, not duplicated by any other substance normally present in the atmosphere, which will permit its detection in extremely small amounts. Second, there should be a simple, rapid, and convenient method for the quantitative estimation of small amounts of the material through this property. Third, the material should be available at reasonable expense in uniform lots large enough to permit the desired use, and it should not deteriorate during storage. Fourth, it should be readily and quantitatively dispersible into the atmosphere at controllable rates and in the required amounts. Fifth, it should be stable while in the atmosphere and its diffusion by atmospheric turbulence should be essentially that of an inert gas. Sixth, it should retain its specific property at least through the sampling and assessment operations and preferably after. Finally, it should be safe to handle and non-toxic to man, animals or plants.

Materials which have been used at least to some extent as tracers include oil fog (Barad and Shorr, 1954), biologicals such as Lycopodium spores (Hay and Pasquill, 1957), gases such as sulfur dioxide (Cramer, 1958b, 1959), radioactive materials such as Xenon 133 (Eggleton and Thompson, 1961), materials such as antimony oxide in which radioactivity may be excited after airborne travel (Haines and Hemeon, 1958), water soluble dyes such as uranine (Robinson et al., 1959; Dumbauld, 1962), and inorganic fluorescent particulates (Grinnell et al., 1946; Leighton et al., 1947; Perkins et al., 1952; Braham et al., 1952; Leighton, 1955; Crozier and Seely, 1955; Hilst, 1957; Cramer, 1958b, 1959; Barad and Fuquay, 1962 ; Bierly and Gill, 1963). 
None of these materials is ideal with respect to all of the requirements for an atmospheric tracer, and any choice must represent a compromise. For some specific uses one material, and for other uses another, may be the best choice. For a limited range of use, where certain requirements may be relaxed, e.g., small scale travel from a ground release over open unpopulated terrain in dry weather, any one of several tracers would be satisfactory. But the wider the intended range of use, the more rigid are the requirements, and the more limited is the range of choice. It is in this category of a wide range of usefulness that the inorganic fluorescent particulates have proven of greatest value as atmospheric tracers.

\section{Properties of inorganic fluorescent particulates suitable for tracer use}

A number of fluorescent inorganic particulates, mostly zinc silicates, zinc sulfides, and zinc-cadmium sulfides, with various elements added in small amounts as activators, have been developed for use as luminescent paint pigments and are commercially available in reasonably uniform lots. Under a microscope with ultraviolet illumination the fluorescence of single particles of most of these materials, down to approximately $0.5 \mu$ diameter or $3 \times 10^{-13} \mathrm{~g}$ in mass, may be observed and the number in a given area counted. The fluorescence thus offers a simple and very sensitive method of detection and quantitative estimation. The materials may be disseminated at low or high rates as single particles, they are safe to handle and non-toxic at any dosage likely to be attained in air, and the fluorescent property is retained indefinitely during storage. It should be emphasized, however, that not all of the available fluorescent pigments are suitable for use as tracers. The fluorescent colors of some are almost indistinguishable from those of naturally occurring substances in air, some are not acceptably stable, and some have too wide a range of particle size distribution.

The best fluorescent colors, i.e., those most readily distinguished from natural fluorescent particles, are yellow and orange. Green and red are acceptable, but blue and white should be avoided. The question of the stability, both fluorescent and chemical, of any material which is being considered should be investigated under the conditions which will be encountered in use, and the material rejected if not found satisfactory.

The particle size distribution may vary substantially, not only between different materials, but also, as illustrated in Table 1, between different lots of the same material. In some cases, the distribution is nearly log normal, in others it approaches a Rosin-Rammler distribution (Rosin and Rammler, 1933). The optimum particle size with relation to ease of counting, airborne behavior, and collection efficiency on impaction-type samplers, is between 1 and $3 \mu$, and the larger the fraction of the particles in this size range the better. Ma- terials with large numbers of either small or large particles should be avoided, since small particles are difficult to count and more likely to be unstable, while larger particles increase fallout losses and decrease the number of particles per unit weight. As a practical guide, not more than approximately $20 \%$ of the particles should be below $1 \mu$, and not more than $5 \%$ above $5 \mu$ in diameter. On this basis, lot A in Table 1 is acceptable but lot $B$ is not, and it should be noted that this difference is not disclosed by the mass mean diameters (MMD) or the number of particles per gram in the two lots.

TABLE 1. Particle size data on two lots of FP 2266.

\begin{tabular}{ccc}
\hline & \multicolumn{2}{c}{ Lot } \\
Size range, $\mu$ & A & B \\
& Per cent of particles \\
\hline 1 & 17 & 34 \\
$2-3$ & 40 & 29 \\
$3-4$ & 25 & 17 \\
$4-5$ & 10 & 10 \\
$>5$ & 4 & 4 \\
Mass mean diameter, $\mu$ & 4 & 6 \\
Number median diameter, $\mu$ & 3.0 & 3.2 \\
Number of particles per gram & $1.7 \times 10^{10}$ & $1.4 \times 10^{10}$ \\
\hline
\end{tabular}

The flow characteristics and dispersibility of the inorganic fluorescent pigments may be improved by treatment with hydrophobic materials. For this purpose, good results have been obtained by blending the pigment with $0.5 \%$ Valron Estersil, a hydrophobic silica product manufactured by du Pont (U. S. Patent No. 2,657,149 issued 27 October 1953).

The fluorescent particulate which has been most widely used by this laboratory is a zinc cadmium sulfide, designated as FP 2266, formerly made by the New Jersey Zinc Company (NJZ) and now made by the United States Radium Corporation (USRC). FP 2267, also made by USRC, is 2266 which has been selected to have a maximum number of particles between $0.75 \mu$ and $3.0 \mu$ in diameter, and which has been treated to improve its flow characteristics.

The fluorescence of FP $2266-7$ is excited by near ultraviolet radiation, and the $3660 \mathrm{~A}$ lines of the mercury arc are a convenient excitation source. When so excited, the fluorescence forms a continuous band extending from blue to red, with a maximum in the yellow. To the eye, the color is yellow, with a spectral hue of $5700 \mathrm{~A}$. When excited by $3660 \mathrm{~A}$, the fluorescence occurs to some extent throughout the particle volume, hence the fluorescent flux per particle is proportional to something between the square and the cube of the particle diameter, approaching the cube as the diameter decreases. The half decay time of the fluorescence, after the exciting light is removed, is approximately one millisecond. 


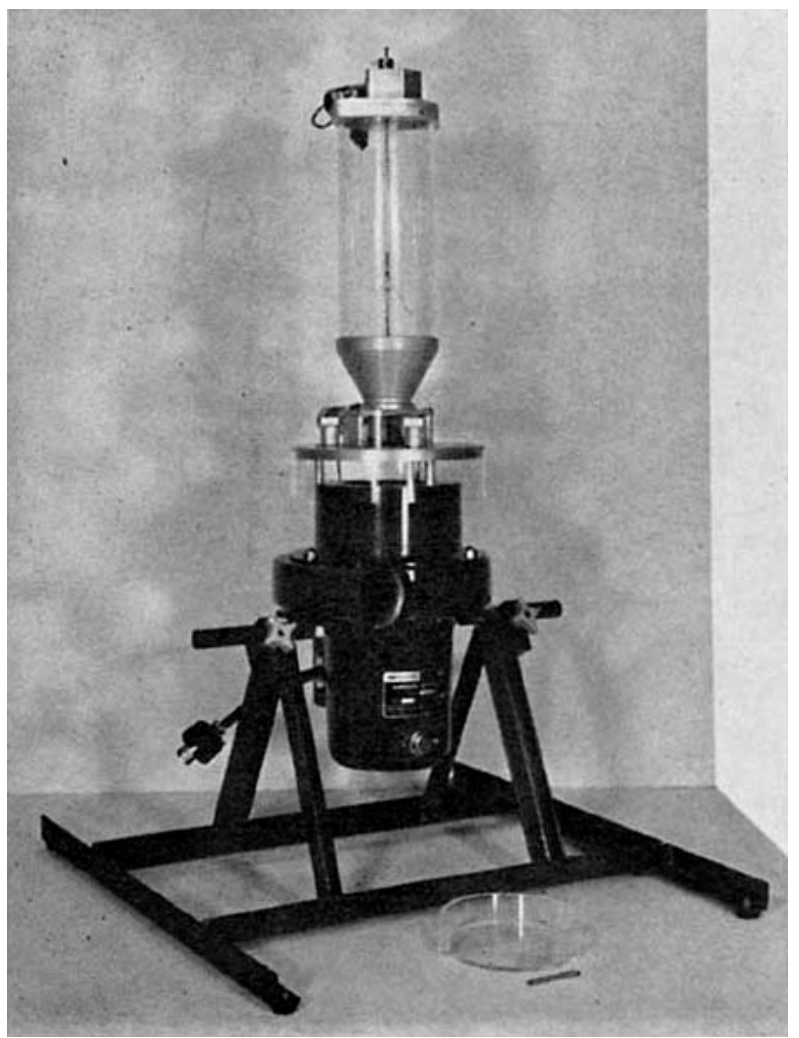

FIG. 1. The blower generator, Model 5.

Under high magnification the individual particles of FP 2266 usually appear to be nodular, i.e., basically nearly spherical or ellipsoidal with small rounded protuberances and occasionally somewhat faceted. About $7 \%$ of the particles appear to be aggregates consisting of 2 or more nodular particles sintered together. Their density is approximately 4 . The material is not affected by water or by heat up to $450 \mathrm{C}$, it dissolves only slowly in strong acids, and appears to be stable with respect to all conditions likely to be encountered in storage and atmospheric travel except one: exposure to sunlight. This effect, which is significant for some lots of material and negligible for others, will be examined in Section $5 \mathrm{~d}$.

When a known mixture of two materials with different fluorescent colors is aerosolized, the relative counts on samples taken after airborne travel agree quite well with those in the starting mixture. The release of the materials from separate sources, with simultaneous sampling on a single array of samplers, provides a means of determining the amount of intermixing of clouds and the relative contributions, at various points, from the separate sources. Two green fluorescing pigments, USRC 2210 and 3206, have been used in conjunction with FP 2267 for this purpose.

One distinct advantage of FP as a tracer is that the samples are not destroyed by the process of assessment, and may be stored as permanent original records. In a number of instances questions regarding sampler per- formance, individual dosages, and particle size distribution have been answered by re-examining stored samples; in one case from trials which had been run over ten years previously.

\section{Equipment}

a. Dissemination. The equipment developed for disseminating the FP tracer is of the generator type, designed for the continuous production of a tracer cloud over a finite time, which may range from less than a minute to several hours. The principal requirements for this type of equipment are that it shall disperse the tracer as an aerosol of single particles, at a desired and constant rate, with a known and reproducible source strength in terms of number of particles disseminated. Ideally, the disseminator should completely deagglomerate the bulk powder into its primary particles, but should not further subdivide these primary particles.

These requirements are closely approached by the blower generator, and this generator has been widely used in the field. In this device, the material to be dispersed is fed from a stirred hopper by a rotating toothed wheel into the intake of a high speed centrifugal blower (Fig. 1). The feed rate may be varied by changing the size and speed of the toothed wheel, and rates ranging from 1 to $250 \mathrm{~g}$. $\mathrm{min}^{-1}$ have been used. The hopper shown in Fig. 1 has a capacity of 2500 grams of FP but may be refilled while in operation if continuous dissemination for long periods is required.

Since the toothed wheel feeds material into the blower by increments, generally from 3 to 10 per second, the output is not time-continuous, an effect which is normally inconsequential due to mixing by atmospheric turbulence, but which must be taken into account when sampling for short times or small cloud travel distances, especially if the generator is carried on a rapidly moving source. The incremental effect may be avoided, at some sacrifice in certainty of operation, by use of a vibrating feed device of the type developed by Bierly and Gill (1963).

With the FP tracer the source strength $Q$ is normally expressed in terms of the number of particles released. In this case $Q=W \cdot F_{S}$, where $W$ is the weight of $\mathrm{FP}$ fed through the generator and $F_{S}$ is the observed number of particles made airborne per unit weight. The method employed for measuring $F_{S}$ from the blower generator uses actual aerosolization with isokinetic sampling in a restricted plume (Leighton, 1955). Comparisons of $F_{S}$, so determined, with the number of primary particles per unit weight in the undispersed material indicate that the dispersal efficiency of the blower generator for surface treated FP is close to unity.

In the dissemination of the tracer from aircraft, feed rates higher than those obtainable from the blower generator are usually required. For this purpose, a broad feed wheel with five groups of offset teeth, which provides a feed rate of $10 \mathrm{lb} \mathrm{min}^{-1}$ from a stirred hopper 
into a downspout extending through the aircraft fuselage, or into an external venturi, using the inflight airstream past the end of the downspout or through the venturi for dispersal, has been employed. However, the source strengths of these devices are difficult to determine and their dispersal efficiency is low; measurements of the horizontal particle flux past a series of samplers mounted on a tower directly downwind of the flight path indicate efficiencies of $60 \%$ or less.

b. Sampling. The first requirements for the sampling device are that it must be able to collect the particles at high dilution in air and deposit them individually on a smooth surface in a manner which is suitable for the excitation of their fluorescence and for counting. The three devices currently in widest use, each of which has both virtues and limitations, are the membrane filter, the drum impactor, and the Rotorod.

Porous cellulose acetate-nitrate membranes, which have been used for FP sampling since 1950, have the advantages that the collection efficiency is virtually $100 \%$, most of the particles are deposited on the upstream face rather than in the pores of the filter, the material is reasonably uniform in permeability, it may be dyed to give a dark background favorable for counting, and after use it may be stored as a permanent original record. The chief disadvantages are that the membranes are fragile and the flow rates attainable are limited. The fragility of the membranes requires a holder with a porous backing; both sintered glass discs and wire screens have been used for this purpose. The current holder (Fig. 2) employs a 100-mesh stainless steel screen, surrounded by a circular magnet, which, with a steel retaining ring, keeps the membrane in place. When desired, a truncated cone for isokinetic sampling may be mounted on the holder. Two sizes of membranes, both circular, 25 and $50 \mathrm{~mm}$ in diameter have been employed. Mounted in their holders, the diameters of the corresponding deposition patterns are 16 and 41 $\mathrm{mm}$, and the deposition areas approximately 2 and 13 $\mathrm{cm}^{2}$.

The flow rate generally used in practice is about 5 liters per min per $\mathrm{cm}^{2}$ of deposition area, and the pressure drop across the membrane required to produce this flow rate is 4 to $5 \mathrm{~cm} \mathrm{Hg}$. The permeability of the membranes varies with the lot of material, and for a given lot at pressure drops up to about $0.2 \mathrm{~atm}$ the flow rate is nearly proportional to the square root of the pressure drop. When adequate pumping capacity is available, a critical orifice may be used in the line to maintain a constant flow rate. The maximum useful sampling period, before the filter surface becomes so loaded with atmospheric particulates as to obscure the fluorescent particles, will, of course, depend on the amount of such material in the air; in clean air, sampling periods of 10 hours or more per filter are quite possible, while in city air the limit may be less than 1 hour.

Although the membrane filter (MF) is primarily

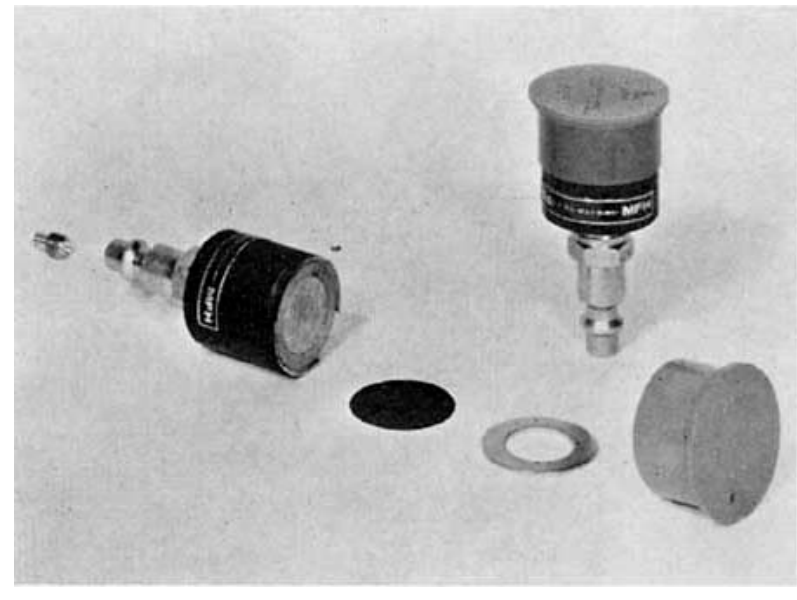

FIG. 2. Membrane filter holder.

useful for total dosage, a sequence may be obtained by changing filters by hand, or by using a bank of filters with a mechanical switching device. A rotary distributor, activated by a clock timer, capable of switching the line from a single pump to each of 12 samplers, has been so used. For operations requiring time resolution, however, such as obtaining time-concentration curves during the passage of a cloud over a stationary location or obtaining cross-sectional and axial concentration curves by traversing a cloud with a sampler mounted in an aircraft, the most satisfactory device is the drum impactor.

In the current model of the drum impactor a strip of aluminum tape, coated on one side with silicone grease or rubber cement, is mounted on a $12.5 \mathrm{~cm}$ diameter drum which is enclosed in a housing so that it can be rotated by increments beneath the rectangular orifice of a conical nozzle (Fig. 3). The orifice, which is generally about $0.7 \mathrm{~mm}$ in width by $7 \mathrm{~mm}$ in length, is oriented at right angles to the direction of rotation of

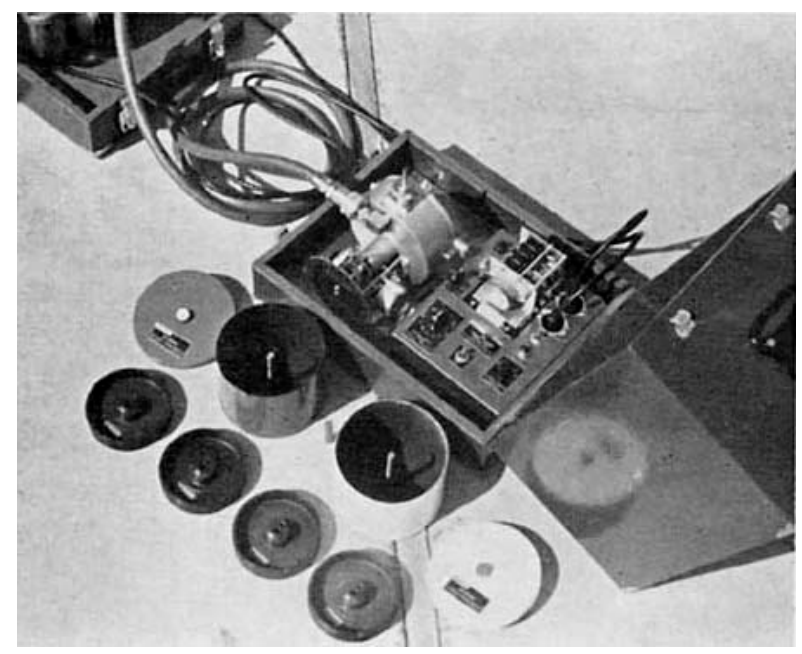

FIG. 3. The drum impactor, Model 63. 


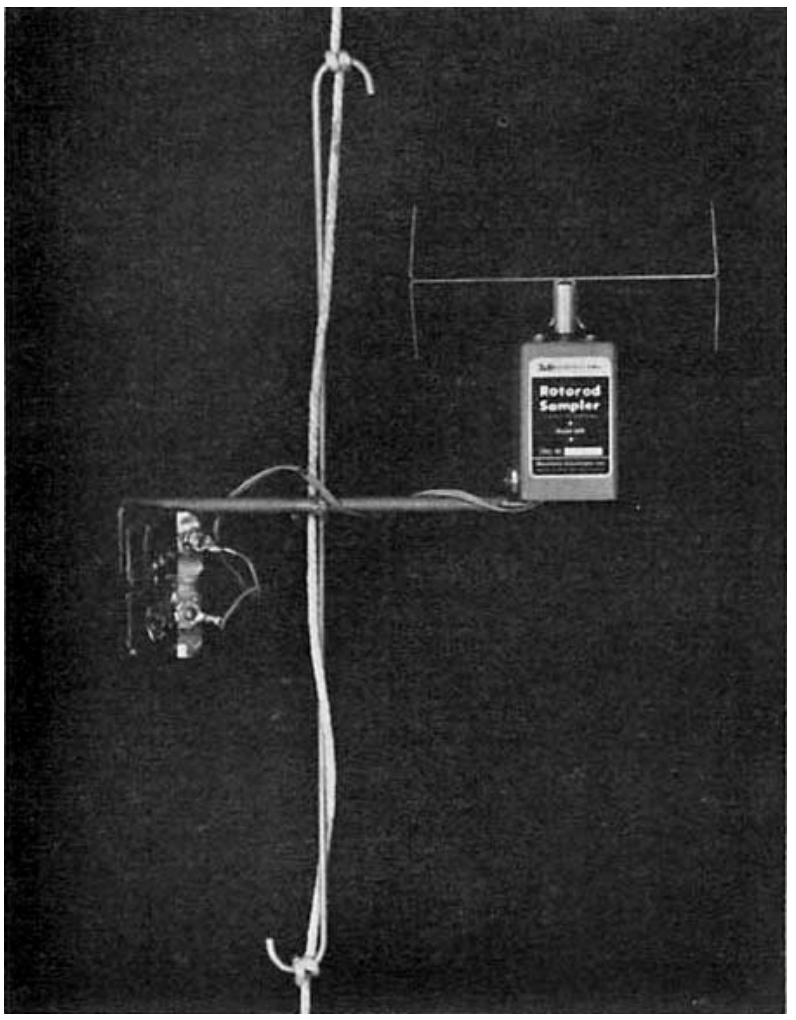

FIG. 4. The Rotorod sampler, equipped for mounting on a balloon cable.

the drum. With a spacing of $3.3 \mathrm{~mm}$ between increments a total of 116 patterns may be obtained on a single tape. The dwell time on any one pattern may be varied from 15 seconds upward, and the time required to move from one pattern to the next is 0.2 second.

The collection efficiency of the drum impactor, as with any impaction device, depends on the jet velocity, the orifice size, the clearance between the orifice and the collecting surface, the nature of the collecting surface, and the materials of which the nozzle and collecting drum are constructed. In early models, using a plastic nozzle and a Scotch tape collecting surface, the collection efficiency was only $\sim 30 \%$, and the central pattern was surrounded by a halo which contained even more particles than the pattern itself. In the current model, using a brass nozzle and a silicone grease or rubber cement on aluminum surface, and adjusting the clearance to maximum pumping efficiency (minimum vacuum to give maximum flow rate) the collection efficiency is $95 \%$ or better and the halo is virtually eliminated.

When so adjusted, the flow rate is $\sim 501 \mathrm{~min}^{-1}$ and the size of the pattern on the collection surface is not much larger than the orifice, hence the flow rate per unit area of collection surface is high, in fact approximately $10001 \mathrm{~min}^{-1}$ per $\mathrm{cm}^{2}$, and on this account the useful sampling period per pattern is limited, generally to 3 minutes or less.
The Rotorod sampler, the virtues of which are its cheapness, simplicity, light weight, and low power requirement, is based on the idea of moving the collector through the air rather than pumping the air past a collector. Two collectors, consisting of thin metal bars coated with silicone grease, are attached by a cross arm to the shaft of a small battery-driven motor so that they are parallel to the axis of rotation (Fig. 4). With collecting surfaces of $0.38 \times 60 \mathrm{~mm}$, a rotation radius of $60 \mathrm{~mm}$, and a rotation speed of $2400 \mathrm{rpm}$, the effective sampling rate of this device is approximately $40 \mathrm{l} \mathrm{min}^{-1}$ or approximately $90 \mathrm{l} \mathrm{min}^{-1}$ per $\mathrm{cm}^{2}$ of surface. Rotation speed and hence sampling rate is constant to $\pm 2 \%$; the power consumption is 0.7 watt.

The chief disadvantage of the Rotorod, in the form described above, is that its collection efficiency is low and is sharply dependent on the particle size. Collection efficiencies observed in field trials with different lots of tracer range from $28 \%$ for a lot of FP 2266 with an MMD of $1.8 \mu$ and a particle per gram count of $7.9 \times$ $10^{10}$, to $73 \%$ for a lot of FP 2267 with an MMD of $3.1 \mu$ and a particle per gram count of $1.6 \times 10^{10}$. It is important to use a standard procedure for coating the collector rods (Webster, 1963) and to determine the collection efficiency with each lot of tracer which is employed.

The collection rate of the Rotorod is little affected by wind speed, $u$, as long as it is smaller than the speed of the collector arm, v $\left(15.1 \mathrm{~m} \mathrm{sec}^{-1}\right.$ for a $60 \mathrm{~mm}$ rotation radius at $2400 \mathrm{rpm}$ ). When $u$ exceeds $v$ the collection rate increases; for $u / v=1.5$ this increase is about $10 \%$ and for $u / v=2$ it is about $22 \%$. High winds also increase the drag on the rod and hence the load on the motor. The use of multiple arms appears to have little effect on the collection efficiency.

The light weight of the Rotorod and the small size of the required battery are advantageous for sampling aloft. In fact, the unit shown in Fig. 4, which weighs $330 \mathrm{~g}$ complete with batteries, was designed for mounting on a balloon cable, and a series of as many as 20 such units, mounted at intervals along the cable, has been used for sampling up to $750 \mathrm{ft}$ aloft.

c. Assessment. The primary task of assessment is to count the particles collected within the deposition area of a sampler. Basically this involves only two requirements, a means of illuminating the particles with ultraviolet radiation to excite the fluorescence, and a means of observing this fluorescence and thereby counting the particles. Since the fluorescence is excited by near ultraviolet radiation, mercury arcs which provide a high intensity in the region of the $3660 \mathrm{~A}$ line of the mercury spectrum may be employed for illumination. For visual counting, a General Electric H85A3 mercury lamp in a light-tight housing equipped with two $50 \mathrm{~mm}$ diameter $\times 96 \mathrm{~mm}$ focal length plano-convex lenses and a Corning 5840 or 5970 filter is mounted above and behind the stage of a monocular microscope so that the arc image is focussed on the stage directly below the objective, 
and a Wratten 2A filter is mounted on the eyepiece. For work requiring very intense illumination in a small area the PEK 109, a high pressure quartz capillary arc manufactured by PEK Laboratories, 825 E. Evelyn St., Sunnyvale, Calif., may be used. With filter and lenses this arc delivers a UV flux about 20 times that from the General Electric H85A3.

In visual counting a $16 \mathrm{~mm}, 0.25$ N.A. achromatic objective and a $10 \times$ eyepiece, giving $100 \times$ magnification, are normally employed. The appearance of a field so magnified, in visible and UV light, is illustrated in Fig. 5. The eyepiece is equipped with a reticule to mark off specific areas in the deposition pattern and the number of particles in each area are counted in turn. Reticules of different degrees of fineness are used for patiterns of different density of population; the best results are obtained when each field of the reticule contains fewer than $\sim 50$ particles. If the sample is heavily populated it is necessary only to count, in randomly selected but known portions, the number of particles necessary to bring the statistical variance within desired limits (Section 5a).

The labor involved in visually counting large numbers of samples directs attention to the possibility of automatic counting. The automatic system developed at Hanford (Barad and Fuquay, 1962), involving irradiation of a membrane filter sample with alpha particles from plutonium and measurement by photomultiplier of the resulting fluorescence from the entire filter, may be used for filters on which $\sim 1000$ or more particles have been deposited. For smaller populations either individual counts or the empty cell technique (Leighton, 1960) are preferable to measurements of total radiation. With ultraviolet illumination, single partticles yield a sufficient fluorescent intensity to permit their detection by photomultiplier, but when deposited on a membrane filter the limiting factor is background radiation from the filter itself. Thus, with a system consisting of a PEK 109 lamp equipped with two $4.5 \mathrm{~mm}$ Corning 5540 CS7-60 filters and a 6127 photomultiplier equipped with Wratten K3 and CC-30 filters, the re-

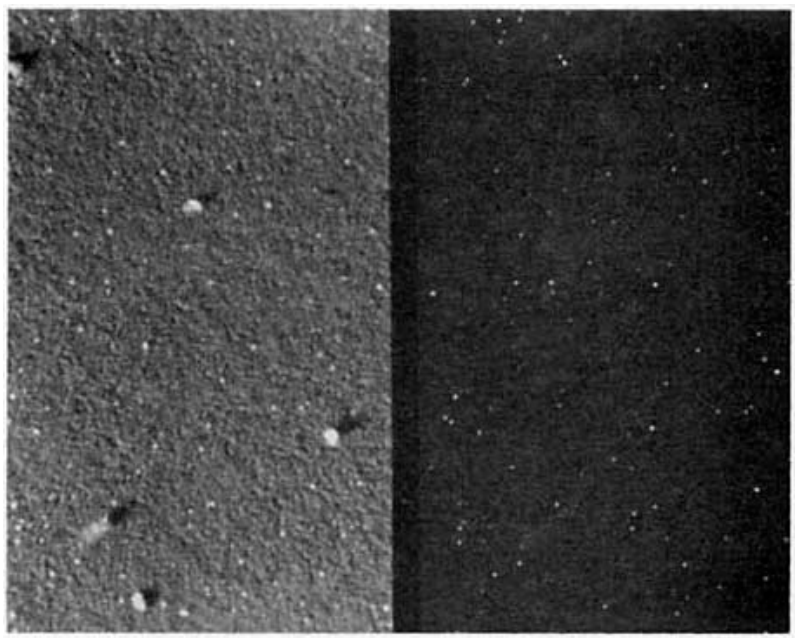

FIG. 5. Photomicrographs of FP collected on a membrane filter; left, under visible light; right, same field under ultraviolet light.

sponses obtained from single particles of FP 2267 are in the range of $10^{2}$ to $10^{5}$ picolumens, while the background light from a membrane filter is from $10^{5}$ to $10^{6}$ picolumens per $\mathrm{mm}^{2}$ on filter surface. To obtain a satisfactory signal to noise ratio under these conditions it is necessary, therefore, to limit the field to a small fraction of a square millimeter.

Whether visual or photoelectric counting is used, the lower limit of particle fluorescence which may be observed will depend on a number of factors, including the intensity of UV illumination, the optical arrangement employed, the nature of both the tracer material and the background, and the visual acuity and the experience of the observer or the sensitivity of the photocell. Since, for small particles, the fluorescent flux approaches porportionality to the cube of the diameter there is generally, for any given arrangement, a fairly sharp lower size limit which may be observed, and with increasing intensity of illumination this limit is extended downward. The counts obtained, therefore, will depend on the illumination intensity to an amount which

Table 2. Operational variation in $F_{S}$ determination.

\begin{tabular}{|c|c|c|c|c|c|c|c|}
\hline$\underset{\text { material }}{\mathbf{F P}}$ & $\begin{array}{l}\text { Lot or } \\
\text { specimen } \\
\text { No. }\end{array}$ & $\begin{array}{l}\text { No. of } \\
\text { tests }\end{array}$ & $\begin{array}{l}\text { No. of } \\
\text { samples }\end{array}$ & $\begin{array}{c}\text { Mean vaiue of } F_{S}, \\
\text { particles } \\
\text { per gram }\end{array}$ & $\begin{array}{l}\text { Rel. std. } \\
\text { error of } \\
\text { the mean, } \%\end{array}$ & $\begin{array}{l}\text { Coefficient } \\
\text { among indiv } \\
\text { Observed } \\
V_{F}\end{array}$ & $\begin{array}{c}\text { f variation } \\
\text { ual samples } \\
\text { Poisson } \\
V_{P}\end{array}$ \\
\hline NJZ 2266 & $9 B M 5$ & 7 & 22 & $5.94 \times 10^{10}$ & \pm 2.9 & 0.132 & 0.049 \\
\hline USRC 2267 & WS-11 & 5 & 15 & $1.33 \times 10^{10}$ & 2.5 & 0.092 & 0.055 \\
\hline USRC 2267 & 128 & 2 & 6 & $1.56 \times 10^{10}$ & 2.4 & 0.054 & 0.047 \\
\hline USRC 2267 & 140 & 2 & 6 & $1.56 \times 10^{10}$ & 4.3 & 0.097 & 0.053 \\
\hline USRC 2267 & 142 & 2 & 6 & $1.38 \times 10^{10}$ & 5.2 & 0.116 & 0.057 \\
\hline USRC 3206 & 129 & 2 & 6 & $1.62 \times 10^{10}$ & 3.2 & 0.071 & 0.046 \\
\hline USRC 3206 & 141 & 2 & 6 & $2.24 \times 10^{10}$ & 5.3 & 0.118 & 0.053 \\
\hline USRC 3206 & 143 & 2 & 6 & $1.64 \times 10^{10}$ & 6.6 & 0.148 & 0.055 \\
\hline \multirow[t]{2}{*}{ USRC 3206} & 145 & $\overrightarrow{2}$ & 6 & $1.33 \times 10^{10}$ & 4.4 & 0.099 & 0.053 \\
\hline & & & & & & ean : 0.103 & 0.052 \\
\hline
\end{tabular}


is in turn dependent on the fraction of very small particles in the material. It is important that for any given series of tests, involving a given lot of material, the same counting equipment and procedures be used throughout, both on field samples and on the samples obtained during source strength determination.

\section{Validity}

a. Operational errors. In dissemination, the chief operational error normally encountered is in the determination of the source strength $Q$. Since the weight of material released may be determined with some precision, the indeterminate error in $Q$ is essentially equal to that in the value used for $F_{S}$, the number of particles per gram. The magnitude of this error, as encountered in source strength determinations with the blower generator is illustrated in Table 2; the corresponding $90 \%$ confidence intervals are mostly in the range of $\pm 5-10 \%$. With other methods of dissemination, such as those depending on the slipstream of aircraft, the uncertainty in source strength may be substantially greater than these figures would indicate.

In sampling and assessment, since single particles of the tracer are observed and counted, the theoretical sensitivity limit is $1 / Q$. For at least two reasons, however, a substantial number of particles must be collected and counted if the result is to have an acceptable quantitative significance. First, small background counts are difficult to avoid, and second, for small

TABLE 3. Variations in dosage among close arrays of membrane filter samplers.

\begin{tabular}{ccccc}
\hline \hline $\begin{array}{c}\text { Field } \\
\text { Expt. No. }\end{array}$ & $\begin{array}{c}\text { No. of } \\
\text { trials }\end{array}$ & $\begin{array}{c}\text { No. of } \\
\text { samples }\end{array}$ & $\begin{array}{c}\text { Coefficients of variation } \\
V_{D}\end{array}$ & $V_{P}$ \\
\hline 138 & 8 & 47 & 0.123 & 0.058 \\
139 & 8 & 48 & 0.093 & 0.041 \\
140 & 8 & 48 & 0.097 & 0.019 \\
141 & 8 & 48 & 0.104 & 0.042 \\
142 & 8 & 48 & 0.105 & 0.044 \\
143 & 6 & 54 & 0.103 & 0.022 \\
& & & Mean $: 0.104$ & 0.038 \\
\hline
\end{tabular}

counts, the statistical uncertainty becomes very large. Thus for a Poisson distribution, such that the coefficient of variation of particle counts, $V_{P}$, is inversely proportional to the square root of the number counted, a count of 10 particles will yield a result which is within $\pm 25 \%$ of the true value only $57 \%$ of the time, and a count of 270 is required to yield a value which has a $90 \%$ probability of being correct to within $\pm 10 \%$. For these reasons, sample counts of fewer than 10 particles are best regarded as not significant, and the quantities of tracer released should be sufficient to yield counts of 100 or more on samples taken throughout the area or the air volume which is of interest.

The magnitudes of the random errors to be expected in sampling and assessment have been investigated in a number of field tests by using closely spaced arrays of samplers at one or more locations, with the results summarized in Tables 3 and 4 . The values of $V_{P}$ given in these tables are the coefficients of variation to be expected as the result of a Poisson distribution in the population of particles, and are based on the number of particles actually counted on each sample. Comparison of these with the observed coefficients of variation $V_{D}$, shows that substantially more than Poisson variability is involved in the determination of dosage with the MF sampler, but not with the Rotorod. Likewise, comparison of the values of $V_{F}$ and $V_{P}$ in Table 2 shows more than Poisson variability in the determination of $F_{\mathrm{s}}$, a result which would be expected from the fact that the samples in these determinations were collected by membrane filter (MF).

The $90 \%$ confidence intervals for dosages from individual samplers, i.e., the intervals about the true dosage within which an individual value will lie $90 \%$ of the time, based on the operational errors disclosed by the close array experiments and the Poisson variance, are shown in Fig. 6. The Rotorod intervals include the statistical uncertainty in collection efficiency corresponding to the rela tive standard errors in Table 4.

Sources of operational error which may lead to still greater uncertainty than that indicated by Fig. 6 include cloud inhomogeneity, sampler position or orientation, impaction or electrostatic deposition, obscuration

TABLE 4. Variation in collection efficiency and individual dosages among close arrays of Rotorod samplers.

\begin{tabular}{|c|c|c|c|c|c|c|c|c|c|}
\hline \multirow[b]{2}{*}{$\begin{array}{c}\text { Field } \\
\text { Expt. No. }\end{array}$} & \multirow[b]{2}{*}{ Lot No. } & \multirow[b]{2}{*}{$\begin{array}{c}\text { Material } \\
\text { MMD } \\
\mu\end{array}$} & \multirow[b]{2}{*}{$\begin{array}{l}\text { Particles } \\
\text { per gram }\end{array}$} & \multirow[b]{2}{*}{$\begin{array}{l}\text { No. of } \\
\text { trials }\end{array}$} & \multirow[b]{2}{*}{$\begin{array}{l}\text { No. of } \\
\text { samples }\end{array}$} & \multicolumn{2}{|c|}{ Collection efficiency } & \multicolumn{2}{|c|}{ Coefficients of variation } \\
\hline & & & & & & $\begin{array}{c}\text { Mean } \\
\text { value } \\
\%\end{array}$ & $\begin{array}{l}\text { Rel. std. } \\
\text { error in } \\
\text { mean, \% }\end{array}$ & $\begin{array}{c}\text { Coefficien } \\
\text { in indiv } \\
V_{D}\end{array}$ & $\begin{array}{c}\text { variation } \\
\text { dosages } \\
V_{P}\end{array}$ \\
\hline 138 & $\mathrm{H} 324-2$ & 2.4 & $3.3 \times 10^{10}$ & 8 & 24 & 54.1 & \pm 1.9 & 0.048 & 0.035 \\
\hline 139 & DPG12-21 & 3.4 & $1.2 \times 10^{10}$ & 8 & 24 & 60.7 & 2.4 & 0.032 & 0.033 \\
\hline 140 & $1339-2$ & 3.1 & $1.6 \times 10^{10}$ & 8 & 24 & 74.7 & 1.8 & 0.040 & 0.040 \\
\hline 141 & $1339-2$ & 3.1 & $1.6 \times 10^{10}$ & 8 & 24 & 73.7 & 1.8 & 0.053 & 0.058 \\
\hline 142 & $1339-2$ & 3.1 & $1.6 \times 10^{10}$ & 8 & 24 & 72.5 & 2.8 & 0.045 & 0.054 \\
\hline \multirow[t]{2}{*}{143} & $1339-2$ & 3.1 & $1.6 \times 10^{10}$ & 6 & 24 & 71.4 & 1.7 & 0.057 & 0.046 \\
\hline & & & & & & & & an : 0.046 & 0.044 \\
\hline
\end{tabular}


by dust or other airborne particulates, non-random distribution of particles over the collector surface, subjective error, particularly with inexperienced personnel, and faulty equipment or procedure.

Data bearing on the effects of meteorological conditions, obtained with close arrays of MF samplers placed approximately 50 yards downwind from a fixed blower generator which was operated for approximately 5 minutes, are summarized in Table 5. Although these results suggest an increase in dosage variation with conditions favoring increased inhomogeneity of the cloud, by the $t$-test the differences are not significant. MF samplers oriented in different directions during these trials, horizontally facing upward and downward, and vertically facing toward and away from the wind, showed no significant variations due to orientation with the exception of the samplers facing into the wind during the thunderstorm in one field test; in this case the values obtained were low, probably due to washoff of the filter surfaces by rain.

The contributions of impaction and electrostatic deposition have been assessed by comparing the number of particles collected on aspirated and unaspirated membrane filters placed side by side and facing into the wind. This comparison indicated that with $25 \mathrm{~mm}$ filters operated at a flow rate of $131 \mathrm{~min}^{-1}$ in a $10 \mathrm{mph}$ wind, at $5 \mathrm{yd}$ from the source $3.2 \%$ of the particles were deposited by impaction and electrostatic deposition, at $15 \mathrm{yd}$ from the source this contribution had decreased to $1.5 \%$ and at $50 \mathrm{yd}$ from the source it was $0.5 \%$. This decrease with distance from the source suggests that the deposition in this instance was mostly electrostatic, due to particle charges acquired during dissemination but rapidly dissipated during airborne travel.

In the obscuration of fluorescent particles by atmospheric particulates which are deposited on the collection surface, the greatest effect is produced by deposition after the FP cloud has passed. Rates of obscuration which have been observed by reoperation of samplers on which $\mathrm{FP}$ had been collected range from 0 to $10 \%$ per hour for membrane filters and 1 to $15 \%$ per hour for Rotorods, depending on the clarity of the air. It is important, therefore, that the period of sampler operation after cloud passage be held to a minimum.

Non-random distribution, which sometimes occurs with high winds on upward oriented membrane filters, may be observed and taken into account during the

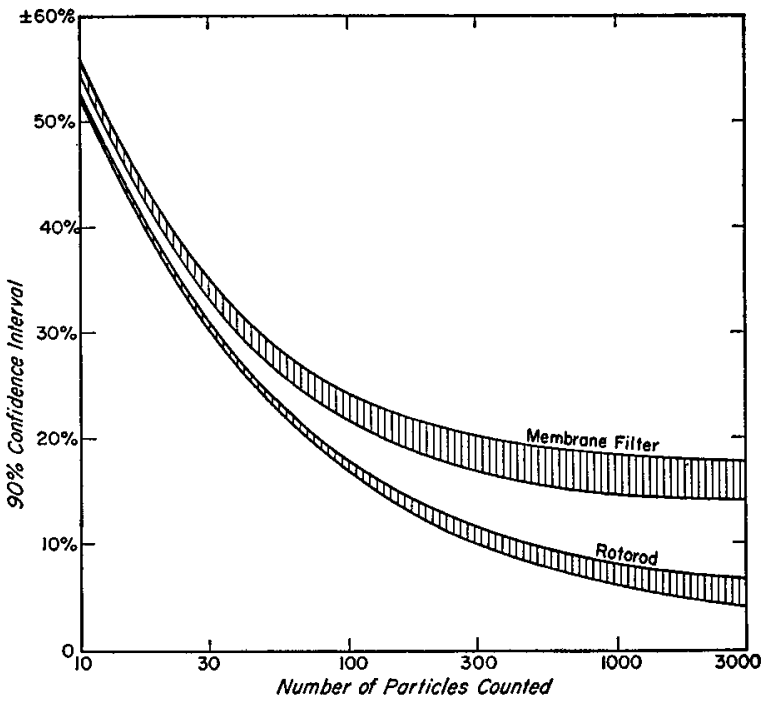

Fig. 6. Confidence intervals for dosages from individual samplers.

analysis. Subjective error, and error due to faulty operation, may often be disclosed by re-examination of the data or equipment if a given result appears to be out of line.

b. Almospheric diffusion. The use of an inorganic particulate of density 4 as a tracer immediately raised the question of possible atypical diffusion of the material during atmospheric travel. Since any such effect should be most marked in a comparison of the diffusion of FP with that of gases, relative diffusion studies of FP and two gases, ammonia and sulfur dioxide, were carried out.

The comparisons with ammonia, which were carried out during the early stages of development of the technique, disclosed no significant differences in behavior over travel distances of up to 120 meters, and showed the importance of using, in such comparisons, both coincidental release and coincidental sampling of the two clouds.

These procedures were adopted in a much more extensive series of comparison between FP and sulfur dioxide. Coincident release was accomplished by feeding both agents into the intake of a modified blower generator, using metering devices which permitted independently variable feed rates of from 2 to $20 \mathrm{~g} \mathrm{~min}^{-1}$ of FP and 200-3000 g min ${ }^{-1}$ of $\mathrm{SO}_{2}$. Coincident sampling was accomplished by drawing the air first through a

TABLE 5. Effect of meteorological conditions on dosage variability with membrane filter samplers.

\begin{tabular}{|c|c|c|c|c|c|}
\hline $\begin{array}{l}\text { Field expt. } \\
\text { No. }\end{array}$ & Conditions & $\begin{array}{l}\text { No. of } \\
\text { trials }\end{array}$ & $\begin{array}{c}\text { No. of } \\
\text { samples }\end{array}$ & $\begin{array}{l}\text { Coefficient of } \\
\text { variation in } \\
\text { dosage, } V_{D}\end{array}$ & $\begin{array}{l}\text { Extreme range } \\
\text { in any trial }\end{array}$ \\
\hline $\begin{array}{l}38 \\
78 \mathrm{~A}, \mathrm{~B} \\
78 \mathrm{C}\end{array}$ & $\begin{array}{l}\text { Stable bayshore wind, } 10-15 \mathrm{mph} \\
\text { Unstable mountaintop wind, } 10-20 \mathrm{mph} \\
\text { Thunderstorm, wind } 30-40 \mathrm{mph}\end{array}$ & $\begin{array}{l}3 \\
2 \\
1\end{array}$ & $\begin{array}{r}21 \\
12 \\
6\end{array}$ & $\begin{array}{r} \pm 0.095 \\
0.122 \\
0.176\end{array}$ & $\begin{array}{l}1.4: 1 \\
1.5: 1 \\
1.7: 1\end{array}$ \\
\hline
\end{tabular}


membrane filter for FP removal, then through an impinger bubbler for $\mathrm{SC}_{2}$. No interference between the two agents was found on passing through the generator, and the presence of sulfur dioxide had no effect on the FP sampling. There was, however, a serious loss in $\mathrm{SO}_{2}$ while passing through the FP sampler, which was found to be due to adsorption on the metal parts of the membrane filter holder in the presence of moist air. This loss was reduced to $5 \%$ or less by coating the metal filter holder with Bakelite varnish. The sulfur dioxide was absorbed in $0.01 \mathrm{M} \mathrm{NaOH}$ containing a small amount $\left(7 \times 10^{-4} \mathrm{M}\right)$ of glycerol, which was found to be superior to benzyl alcohol as a bisulfite oxidation inhibitor, and determined by the fuchsin-formaldehyde colorimetric method.

Eight exploratory and 24 full scale field trials were conducted using 51 samplers distributed concentrically with a $7 \frac{1}{2}^{\circ}$ spacing along arcs of 44,91 , and 183 meters radius from the source. In addition, during the last nine trials 9 portable samplers were operated at downwind distances of 238 to 366 meters from the source. For each test the release period was 5 minutes and the typical amounts of $\mathrm{FP}_{\text {and }} \mathrm{SO}_{2}$ made airborne were, respectively, 25 and 11,000 grams. Wind speed varied from 1 to $7 \mathrm{~m}$ $\mathrm{sec}^{-1}$ and stability conditions from strong lapse (day) to strong inversion (night) during the trials. Light rain occurred just before or during three of the trials.

To facilitate the comparison of the two agents, all sampling results were converted to dosage per unit source strength, $D / Q . D$ and $Q$ were measured in grams for $\mathrm{SO}_{2}$ and in number of particles for FP. Since these units cancel in the ratio $D / Q$, and by virtue of coincident sampling the two agents were sampled with the same flow rate, for ideal behavior and perfect technique the ratio $(D / Q)_{\mathrm{FP}} /(D / Q)_{\mathrm{SO}_{2}}$ should be unity.

In analyzing the data three bases of comparison of the two agents were used: isodosage areas, crosswind integrated dosages (CWID), and the dosage ratios at individual sampling stations. The results are summarized in Table 6.

In drawing the contours to be used for isodosage area comparisons, the same $D / Q$ levels were used for both agents. Subjectivity was minimized by encoding the data so that neither the trial number nor the agent was

TABLE 6. FP/SO $/ \mathrm{SO}_{2}$ comparison ratios.

\begin{tabular}{|c|c|c|c|c|}
\hline & $\begin{array}{l}\text { No. of } \\
\text { cases }\end{array}$ & $\begin{array}{c}\text { Geo- } \\
\text { metric } \\
\text { mean } \\
\text { ratio, } \\
\mathrm{FP} / \mathrm{SO}_{2}\end{array}$ & $\begin{array}{l}\text { Vari- } \\
\text { ance } \\
\text { factor }\end{array}$ & $\begin{array}{l}\text { Extreme } \\
\text { range }\end{array}$ \\
\hline Isodosage area ratios & 59 & 0.98 & 1.29 & $0.31-1.45$ \\
\hline Dosage-area product ratios & 24 & 1.03 & 1.14 & $0.83-1.39$ \\
\hline CWID ratios & 69 & 1.08 & 1.38 & $0.43-1.91$ \\
\hline \multicolumn{5}{|l|}{ Individual dosage ratios: } \\
\hline Exploratory trials & 23 & 0.97 & 1.27 & $0.62-1.40$ \\
\hline Full scale trials & 337 & 1.07 & 1.67 & $0.35-3.2$ \\
\hline
\end{tabular}

known to the evaluator, and as a test of reproducibility twelve sets of data involving 42 contours were independently reevaluated. For the two sets of evaluations, a value of 1.057 was obtained for the variance factor, the antilogarithm of the coefficient of variation of the logarithms of the ratios.

Comparisons of the areas within the contours for FP and $\mathrm{SO}_{2}$ were made in two ways: on the basis of the ratio of areas within each pair of isodosage contours, and on the basis of the ratio, for each trial, of the dosage area products, $\int \mathcal{S} c d t d A$, the integral of concentration, $c$, with respect to time, $t$, and to area, $A$. The data, summarized in Table 6 , were analyzed with respect to meteorological categories, and the $t$-test applied to the ratios for each meteorologically similar category, with the conclusion that the two agents were equally responsive to meteorological changes and showed no statistically significant differences in area coverage under any of the meteorological conditions which were encountered.

The CWID ratios were analyzed with respect to variation with downwind distance and with meteorological conditions. The results, expressed as slopes of $\log$ CWID/log distance lines, are summarized in Fig. 7. Random distribution tests and a distribution-free

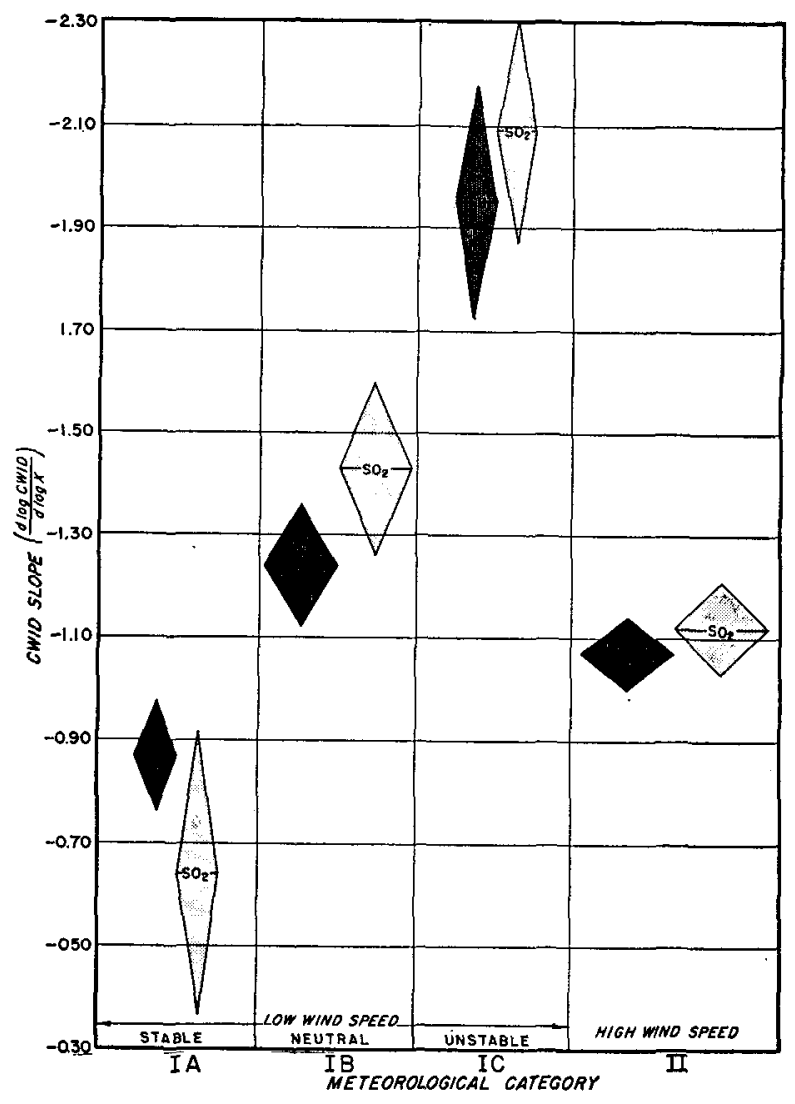

FIG. 7. Comparison by meteorological categories of $\mathrm{FP}$ and $\mathrm{SO}_{2}$ CWID slope data. The half height of each diamond is equal to one standard error, the width is proportional to the number of trials. 
analysis disclosed no significant differences, either between the CWID ratios or the CWID-distance slopes for the two agents.

The dosage ratios yielded by individual samplers were analyzed with respect to their distribution about a central value, the slope of a plot of $\log (D / Q)_{\mathrm{SO}_{2}}$ vs. $\log (D / Q)_{\mathrm{FP}}$ for all data, application of the $t$-test to similar plots for individual trials, and application of the distribution-free method to the ratios at each sampling distance in each trial. The latter indicated an apparently significant attenuation in the $\mathrm{SO}_{2}$ dosage with downwind distances, relative to $\mathrm{FP}$, in two afternoon trials under strong lapse conditions. With this exception, the dosage ratios showed no significant departures from unity by any test.

The overall conclusion from the FP-SO $\mathrm{S}_{2}$ comparison trials is that, within the range of travel distances and meteorological conditions represented, any differences in atmospheric diffusion are too small to be resolved by the field test methods which were employed. No evidence of atypical behavior on the part of FP was found; indeed, insofar as the dosage areas and CWID-distance slopes were concerned, the differences between the two agents were smaller than the differences between meteorologically similar trials with the same agent.

c. Fallout and impaction. In the absence of other removal processes it may be expected that all FP released in the air will, by sedimentation, eventually reach the ground. The fraction which has reached the ground at any given time, i.e., the fallout loss, will depend on the particle size distribution of the material used, the sedimentation velocity over this size range, the height of the cloud, and the amount of vertical mixing by atmospheric turbulence.
Since most individual particles of FP approach spherical dimensions, it may be assumed that their settling velocity in quiescent air approaches the Stokes velocity, which for spherical particles of the density of FP and diameter $d$ in microns, in air at normal temperature and pressure, is $0.012 d^{2} \mathrm{~cm} \mathrm{sec}^{-1}$. Thus a $1 \mu$ particle of FP in quiescent air may be expected to require approximately 140 minutes to fall 1 meter, while a $5 \mu$ particle will fall this distance in about 5.5 minutes.

Due to the $d^{2}$ relation, the fallout loss on a number basis will be smaller for a tracer material with a distribution of particle sizes than it would be for a uniform tracer material with the same density and MMD. For example, the loss due to Stokes settling, from a uniform cloud in quiescent air, of material A in Table 1 would be $55 \%$ at the time at which it would reach $100 \%$ if the particle size were uniform. For low level releases of tracer, another factor which reduces fallout loss is vertical mixing by atmospheric turbulence. The extent of this effect, estimated for several conditions of vertical mixing, is illustrated in Fig. 8 for a material of uniform particle size. Combining curve $B$ of this figure with the particle size distribution of an actual lot of FP (material A of Table 1) leads to the estimate of fallout loss as a function of cloud height in Fig. 9.

Field measurements of fallout loss have been conducted by measuring the amount of material collected on vaseline coated plates at ground level and varying distances from the source. The vaseline coating was used because plates so coated, whether of glass or metal, collected 10 to $15 \%$ more particles than did uncoated glass while uncoated metal plates when close to the generator collected an atypical number of small particles, possibly due to electrostatic deposition. In

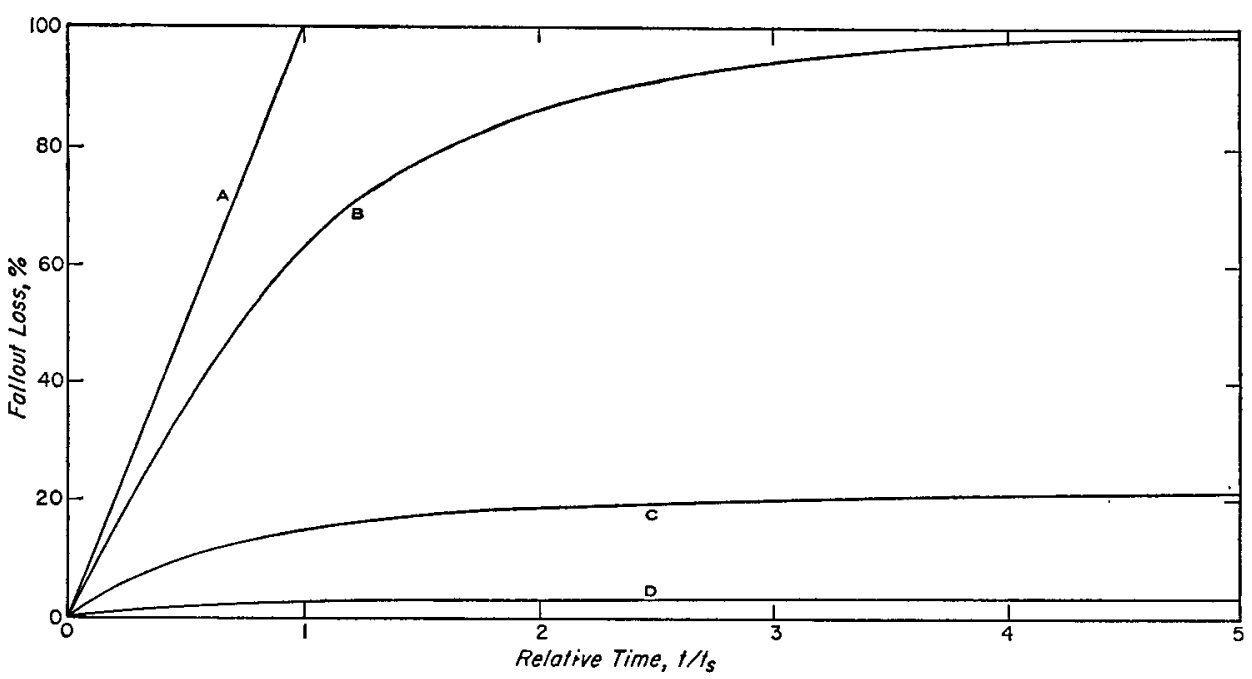

FIG. 8. Estimated effect of atmospheric mixing on fallout loss. $A=$ Stokes settling in quiescent air for a material of uniform particle size, uniformly dispersed to initial height $Z_{i} ; 100 \%$ loss occurs in time $t_{s}$. $B=$ Uniform mixing maintained to constant height $Z_{i}$. $C=$ Uniform mixing maintained to a height increasing from $Z_{i}$ at a rate of $\Delta Z / \Delta X=0.01$, with a wind velocity of $3 \mathrm{mph}$ and 2.5 u particles of density 4 . $D=$ Same as $C$, except $\Delta Z / \Delta X=0.1$. 
one series of measurements, the plates were set out from 1.2 to $39 \mathrm{~m}$ downwind in order to determine the initial fallout loss from a blower generator plume at a release height of $56 \mathrm{~cm}$ above the ground. With untreated FP 2266 , the losses ranged from 12 to $18 \%$ by weight of the material released, and consisted chiefly of clumps of particles $30 \mu$ or more in diameter; with surface-treated material the loss was reduced to less than $1 \%$.

In another series of trials, involving travel distances up to one mile across urban areas, it was found that the number of particles collected per unit area on each plate was approximately proportional to the dosage at the plate position. With this proportionality constant, $k$, it follows that the total fallout loss up to travel distance $x$ should be

$$
N_{f}=k \int \mathrm{CWID} d x
$$

where CWID is the crosswind integrated dosage. Assuming this relation, it becomes possible to estimate from the glass plate and dosage data the total sedimentation loss for different distances of cloud travel.

The average of such estimates for eight trials in Winnipeg, five of which were at night, are shown in Fig. 10. The average wind velocity during these trials was $1.4 \mathrm{~m} \mathrm{sec}^{-1}$. In another series of four trials in highly urbanized St. Louis, all at night with average wind speeds of $1.7 \mathrm{~m} \mathrm{sec}^{-1}$, the average fallout loss up to approximately one mile of travel was $0.45 \%$. Vertical sampling showed that the rate of rise of the cloud during these trials was substantial, approaching or even exceeding the $\Delta Z / \Delta X=0.1$ of curve $D$ in Fig. 8 . The

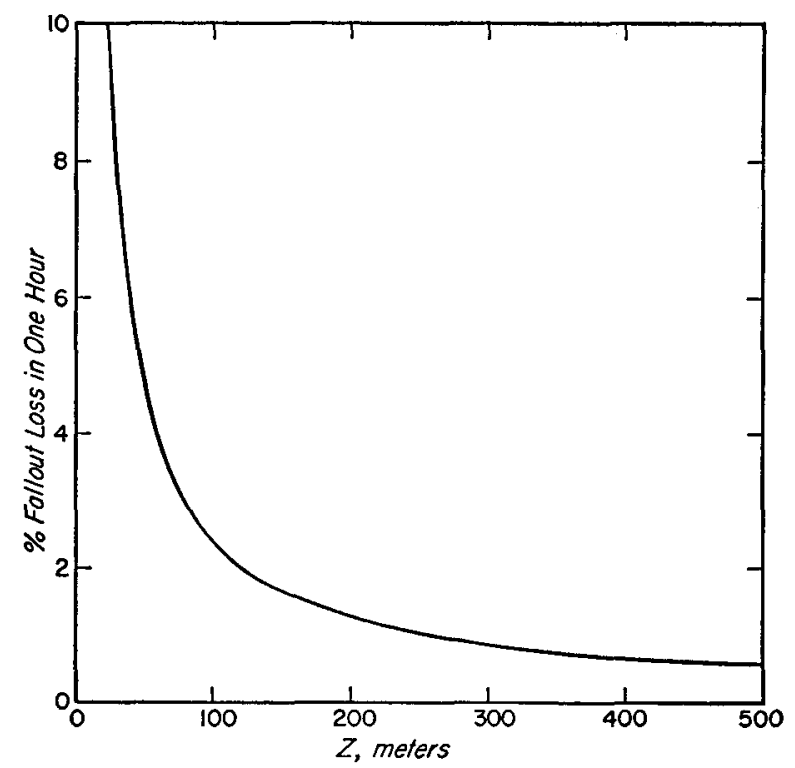

FIG. 9. Fallout loss as a function of cloud height. Estimated for FP material $A$ of Table 1, under conditions which maintain uniform mixing to a constant height $Z$. small observed losses are therefore consonant with the predictions of this figure.

During one tracer trial over Palo Alto, conducted during the afternoon with a surface wind of $2.7 \mathrm{~m} \mathrm{sec}^{-1}$ and an overhead inversion at $90 \mathrm{~m}$, the number of particles deposited on leaves collected at distances up to 4.5 miles from the source were measured by microscopic examination. From the results, together with an estimate of the total leaf area $\left(2.5 \times 10^{9} \mathrm{~cm}^{2}\right.$ per sq mi or about $10 \%$ of the ground area), it was concluded that $3.4 \%$ of the material released was deposited on leaves during 4.5 miles of travel.

Most of the particles were deposited on the edges of the leaves, and most of the deposition occurred near the source. The concentration of the deposition on the leaf edges suggests that of the two processes, fallout and impaction, which might cause deposition on leaves, in this case impaction was the more important. The concentration near the source is consonant with the facts that the cloud was released near ground level and apparently diffused upward by vertical mixing with $\Delta Z / \Delta X \sim 0.1$ until it reached the inversion base. The total fallout during 4.5 miles of travel under these conditions may be estimated from Figs. 8 and 9 at between 3 and $4 \%$, which would indicate that in this trial the losses from fallout and impaction were comparable.

In general, impaction loss during cloud travel over wooded areas may be expected to increase with wind velocity, leaf density, and with the fraction of the cloud which is below treetop level. In addition, it may be expected to be a function of the leaf nature; pine needles should be more efficient impactors than broad leaves.

d. Fluorescent stability. With most of the fluorescent zinc sulfide and zinc cadmium sulfide pigments, exposure to sunlight or to UV irradiation produces a reversible surface darkening in the bulk powder and irreversibly changes the fluorescence of some of the single particles. Early in the development of the FP tracer system the extent to which these effects might alter

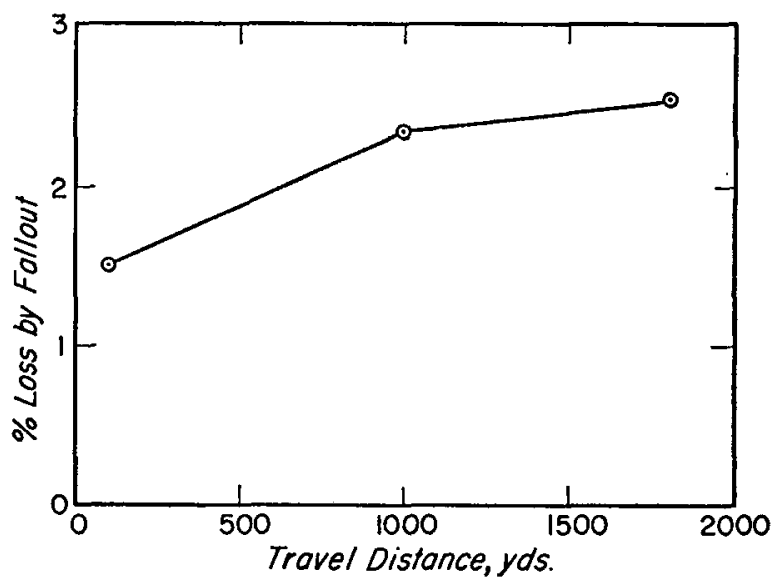

Fig. 10. Average fallout loss as a function of travel distance for eight tracer trials in Winnipeg. 
particle counts was investigated with the NJZ 2266 which was then in use. In these tests the fluorescence of over six hundred particles, dispersed on glass plates, was individually noted and recorded before and after successive periods of exposure to sunlight. Expressed in terms of percentage per plate, the fluorescence of $3 \%$ to $9 \%$ of the particles was reduced below detectable limits by exposure to sunlight for 3 to 15 hours. The effect was greatest during periods of high humidity, all of the particles so affected were below $1 \mu$ in diameter, most of the quenching occurred during the first few hours of irradiation, and few additional particles were lost even with long exposures. In addition, $15 \%$ to $25 \%$ of the particles showed changes which did not prevent their being counted. Some of these showed changes in fluorescent intensity over the entire particle, some appeared to change only in spots, and some showed evidence of a shift in the fluorescent radiation toward longer wavelengths. From $70 \%$ to $80 \%$ of the particles showed no changes detectable by eye, even with exposures of 16 to 18 hours.

More recently, Eggleton and Thompson (1961) have reported losses of up to $50 \%$ of the particles of a zinc cadmium sulfide pigment, made by Derby Luminescents, during about 2 hours of airborne travel in sunlight. This led to a reinvestigation of the fluorescent stability, both of the original NJZ 2266 and of several current materials, including that of Derby Luminescents.

In this reinvestigation, particles of each material were collected on membrane filters, counted, exposed to ultraviolet radiation, and again counted. In most of the exposures the filters were placed in a closed chamber containing air at $100 \%$ relative humidity, and irradiated for 8 hours with mercury arcs which gave an ultraviolet intensity at the filter surface about $1 \frac{1}{2}$ times that of normal noon sunlight. The air temperature during the irradiations was maintained at $125 \mathrm{~F}$ and the temperature of the filter surface was $125-130 \mathrm{~F}$. In one series of tests the relative humidity in the chamber was reduced to $20 \%$, and in another series, the filters were exposed to direct sunlight with aspiration in ambient air. In counting, the filters were illuminated in some cases with the standard H85A3 lamps, and in others, to obtain higher intensity, with the PEK-109 lamp. Counts were made by standard procedures.

The results, summarized in Table 7 , show a wide range of stabilities among the materials tested. The low losses shown by the NJZ 2266 confirm the earlier measurements on this material, and the high losses shown by the Derby $1318 / 10$ are in line with the observations of Eggleton and Thompson. Fig. 11 gives photographic evidence of this difference. On the basis of both its fluorescent instability and its excessive numbers of small particles, $44 \%$ below $1 \mu$ for lot 8231 , the Derby material should be rejected as unsuitable for tracer use.

The tests with USRC 2267 show that differences in stability may be expected even among different lots of the same material. Lot 1339-2 of USRC 2267 appears to be nearly as stable as the standard NJZ 2266, while the other lots are questionable. Of the two lots of green fluorescing material tested, USRC 3206 and 2210, the latter was the more stable.

Comparison of columns A and B of Table 7 shows that increasing the illumination intensity during counting results in every case in an increase in particle loss. This is probably due to the fact that most of the unstable particles are small, and with increasing illumination the threshold of observable particle diameters is moved downward, thus bringing more of the unstable particles in to the original count.

Decreasing the relative humidity during irradiation from $100 \%$ to $20 \%$ (Column C) decreased the percentage of particles lost with every material so tested. The apparent gain shown by three of the results in this column may be due either to the brightness increase which will be described below, or to the statistical variation involved in counting. In this series of tests the

TABLE 7. Effect of ultraviolet irradiation on particle counts.

\begin{tabular}{|c|c|c|c|c|c|c|c|}
\hline \multirow[b]{2}{*}{ Material } & \multirow[b]{2}{*}{ Lot No. } & \multirow{2}{*}{$\begin{array}{l}\text { Particles } \\
\text { per gram }\end{array}$} & \multirow{2}{*}{$\begin{array}{c}\% \text { of particles } \\
\text { below } 1 \mu\end{array}$} & \multicolumn{4}{|c|}{$\begin{array}{l}\text { Percentage reduction in particle counts for } \\
\text { irradiation and counting conditions } \\
\text { stated below. }(\mathrm{G}=\mathrm{Gain})\end{array}$} \\
\hline & & & & A & $\mathrm{B}$ & $\mathrm{C}$ & $\mathrm{D}$ \\
\hline NJZ 2266 & 8BG505 & $3.3 \times 10^{10}$ & 21 & 1.0 & 8.2 & $(7.4 \mathrm{G})$ & 7.1 \\
\hline USRC 2267 & $1339-2$ & $1.7 \times 10^{10}$ & 12 & 2.0 & & (1.6G) & 2.4 \\
\hline USRC 2267 & WS-11 & $0.97 \times 10^{10}$ & & 12.0 & & $(2.7 \mathrm{G})$ & 16.0 \\
\hline USRC 2267 & $12-21$ & $1.2 \times 10^{10}$ & 9 & 15.2 & 22.8 & & \\
\hline USRC 3206 & H324 & & & 26.7 & 26.8 & 7.1 & 4.1 \\
\hline USRC 2210 & 0067 & $1.35 \times 10^{10}$ & & 10.8 & 14.1 & & \\
\hline Derby $1318 / 10$ & 8231 & & 44 & 43.5 & 47.7 & 6.9 & \\
\hline Derby $1318 / 10$ & 8336 & & & 30.7 & 37.3 & 4.4 & \\
\hline
\end{tabular}

Irradiation and counting conditions:

A. 8 hours irradiation by UV at $1 \frac{1}{2} \mathrm{X}$ sunlight in air at $125 \mathrm{~F}$ and $100 \% \mathrm{RH}$; counting by fields or traverses with standard microscope illumination.

B. Same as A except intense (PEK-109) microscope illumination.

C. Same as A except air during irradiation was at $20 \% \mathrm{RH}$.

D. 19 hours irradiation by sunlight on aspirated filters in ambient air, counting with standard illumination. 


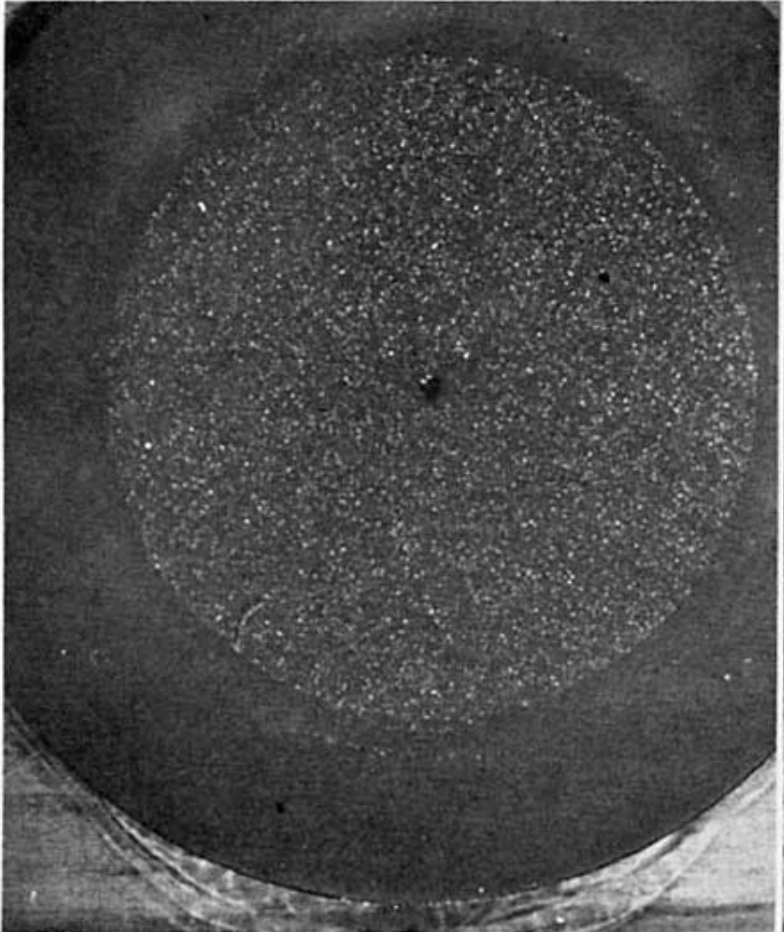

a) NJZ 2266 before exposure.

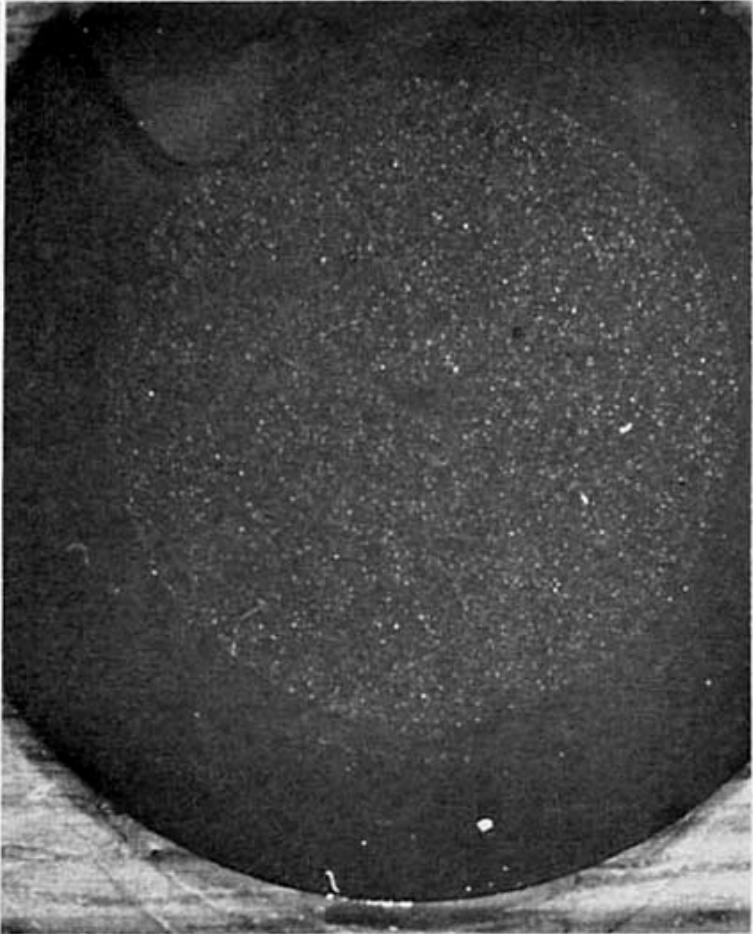

b) NJZ 2266 after exposure.

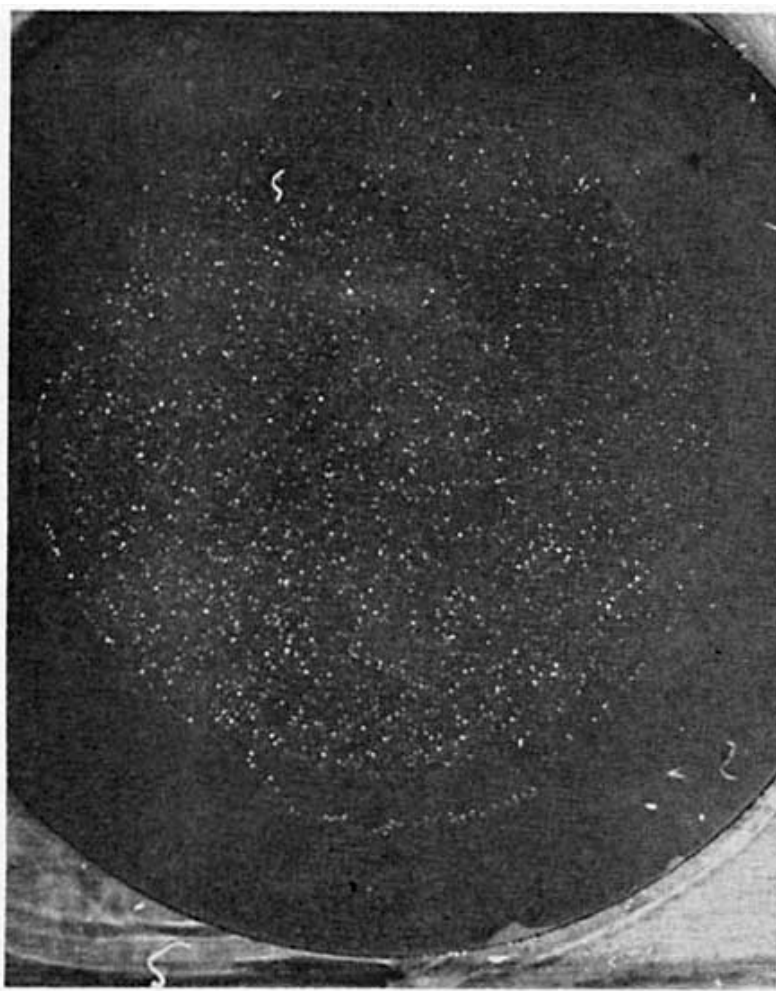

c) Derby $1318 / 10$ before exposure.

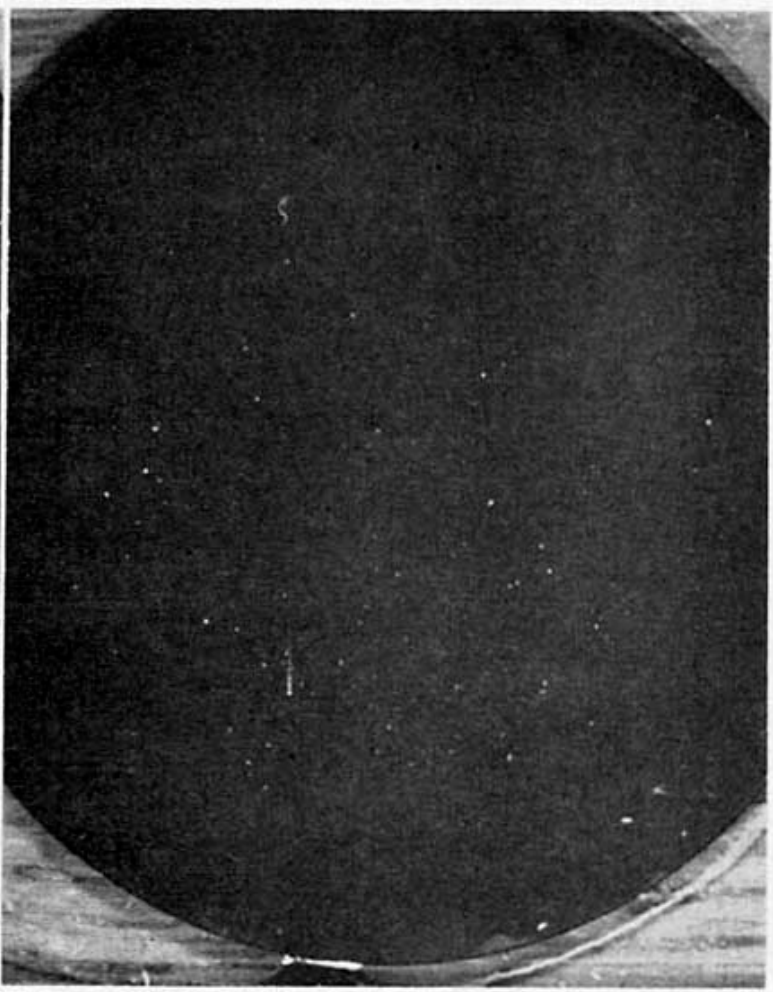

d) Derby 1318/10 after exposure.

FIG. 11. Comparative fluorescence of NJZ 2266 and Derby 1318/10 before and after 8 hours of UV irradiation on membrane filters at an intensity of $1 \frac{1}{2} \mathrm{X}$ sunlight. Throughout the irradiation period the filter surface was $125-130 \mathrm{~F}$ and surrounding air was $100 \%$ relative humidity. Using standard counting procedures, the average loss in particle count as a result of irradiation was $1 \%$ for NJZ 2266 and $43.5 \%$ for Derby $1318 / 10$. The darker backgrounds in the irradiated samples are due to an actual darkening of the filters; the rupture in the upper photographs also occurred during irradiation. 
average number of particles counted per filter was 360 , and three such counts were made on each filter before and after exposure. For a Poisson distribution the corresponding $90 \%$ confidence interval in the ratio of the mean counts is $\pm 8.9 \%$. All of the ratios obtained in the low humidity tests depart by less than this interval from unity, hence none of the materials tested showed a significant change. The same conclusion applies to three of the four materials which were exposed to sunlight for 19 hours (Column D of Table 7 ). In this case, only lot WS-11 showed a significant reduction in particle count, and this may have been due to obscuration by air pollution particulates which were deposited during the 19 hours of aspiration.

Measurements by photomultiplier of the fluorescent brightness, before and after UV irradiation, of 100 individual particles of NJZ 2266 and 100 of Derby $1318 / 10$, mostly in the $1-5 \mu$ size range in each case, yielded the results shown in Table 8 . The brightnesses recorded after irradiation may be somewhat high due to increased reflectivity of the filter material on which the particles were deposited, and particularly the apparent increase in brightness of the NJZ 2266 may be due to this effect. With this reservation, the data in Table 8 support the conclusion from the counting tests regarding the difference in fluorescent stabilities between the two materials.

\section{Discussion}

The zinc cadmium sulfide phosphors which are used as FP material are manufactured by a batch process in which there is considerable variability in the size range, the fluorescent hue, the intrinsic brightness, and the fluorescent stability under irradiation. For this reason, when it is proposed to use the tracer in accurately controlled and instrumented atmospheric diffusion experiments it is essential that the particle size distribution and the fluorescent properties of each lot of material be tested and judged satisfactory before it is put into use. By this procedure, it may be assured that the material is suitable for counting and that fluorescence loss will not be a significant source of error.

The evidence presented in the preceding sections indicates that for ground releases of tracer the losses by fallout and impaction may amount to from 1 to $10 \%$

TABLE 8. Effect of ultraviolet irradiation on fluorescent brightness.

\begin{tabular}{|c|c|c|c|}
\hline & \multicolumn{2}{|c|}{$\begin{array}{l}\text { Av. fluorescent } \\
\text { brightness, picolumens }\end{array}$} & \multirow{2}{*}{ 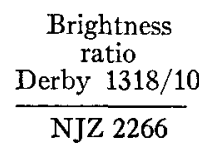 } \\
\hline & $\begin{array}{l}\mathrm{NJZ} \\
2266\end{array}$ & $\begin{array}{l}\text { Derby } \\
1318 / 10\end{array}$ & \\
\hline $\begin{array}{l}\text { Before irradiation } \\
\text { After irradiation* }\end{array}$ & $\begin{array}{l}4100 \\
4400\end{array}$ & $\begin{array}{l}2500 \\
1050\end{array}$ & $\begin{array}{l}0.62 \\
0.24\end{array}$ \\
\hline
\end{tabular}

$* 8$ hours at $1 \frac{1}{2} \mathrm{X}$ sunlight in air at $125 \mathrm{~F}$ and $100 \% \mathrm{RH}$. during the first few miles of travel, depending on the rate of rise of the cloud with turbulent mixing and the nature of the ground cover. For releases from aircraft, of course, there will be no losses from these sources until the cloud reaches the ground. For large travel distances, very little evidence is available on the rate of attrition by fallout and impaction. From Fig. 9, if the cloud height is above 100 meters the fallout loss should be below $2 \%$ per hour, and the observed decrease in fallout rate with increasing cloud height would appear to support this estimate.

The extent to which FP are removed from the atmosphere by rain has not been established. In two cases in which some rain fell during trials the dosages obtained did not appear to be significantly altered. Estimates based on the Langmuir accretion theory lead to the tentative conclusion that for particles of the size range and density of FP the amount of washout depends on the total precipitation rather than the intensity of rainfall (Vaughan and Perkins, 1961). For wettable particles of density 4, the computed losses for $25 \mathrm{~mm}$ of rain would be $10 \%, 78 \%$, and $98 \%$ for particles of $1.5,2$, and $2.5 \mu$ diameter, respectively. For non-wettable particles the computed loss is negligible even for heavy rainfall. The wettability of the particles is, therefore, a critical factor, and for FP this remains to be determined.

In summary, the operational errors inherent in the FP technique in its present state of development set limits, in terms of $90 \%$ confidence intervals, of approximately $\pm 5-10 \%$ for source strength determination with the blower generator, of $\pm 10-12 \%$ (for 300 particles counted) for individual dosages determined by the Rotorod, and $\pm 17-20 \%$ for those determined by the membrane filter sampler. Of the three behavioral aspects of $\mathrm{FP}$ which have been investigated, the effects of atypical diffusion on the validity of the method appear to be insignificant, and fluorescence losses may be controlled by proper selection of material. Fallout and impaction losses, on the other hand, may produce significant errors unless they are evaluated and a correction applied.

Acknowledgment. Material contributions by Robert W. McMullen, Theron S. Brown, George M. Kohler, and Douglas R. Longwell to the work reported here are gratefully acknowledged.

\section{REFERENCES}

Barad, M. L., and J. J. Fuquay, editors, 1962 : Green Glow Diffusion Program Vol. I. HW71400-Vol. 1, 77 pp. [OTS, U. S. Department of Commerce, Washington 25, D. C.]

- , and X. Shorr, 1954: Field studies in diffusion of aerosols. Amer. Indus. Hyg. Assoc. Quart., 15, 136-140.

Bierly, E. W., and G. C. Gill, 1963: A technique for measuring atmospheric diffusion. J. Appl. Meteor., 2, 145-150.

Braham, R. R., B. K. Seely and W. D. Crozier, 1952: A technique for tagging and tracing air parcels. Trans. Amer. Geophys. Union, 33, 825-833.

Cramer, H. E., et al., 1958a: The study of diffusion of gases or aerosols in the lower atmosphere. AFCR-TR-58-239, AF19- 
(604)-1058, 69 pp. [Defense Documentation Center, AD 152582$.

__ et al., 1958b: Diffusion measurements during Project Prairie Grass. Geophy. Res. Paper No. 59, AFCR-TR58-235(I), 57-201. [Defense Documentation Center, AD 152572$.

_- et al., 1959: The study of diffusion of gases or aerosols in the lower atmosphere. AFCR-TR-59-207, AF19-(604)-3460, 33 pp. [Defense Documentation Center, AD 210482. .]

Crozier, W. D., and B. K. Seely, 1955: Concentration distributions in aerosol plumes three to twenty-two miles from a point source. Trans. Amer. Geophys. Union, 36, 42-52.

Dumbauld, R. K., 1962: Meteorological tracer techniques for atmospheric diffusion studies. $J$. Appl. Meteor., 1, 437-443.

Eggleton, A. E. J., and N. Thompson, 1961: Loss of fluorescent particles in atmospheric diffusion experiments by comparison with radioxenon tracer. Nature, 192, 935-936.

Grinnell, S. W., W. A. Perkins, F. X. Webster and P. A. Leighton, 1946: Bimonthly Report No. 2, Contract W-18-035-CWS1256. [Stanford University.]

Haines, G. F., Jr., W. C. L. Hemeon and H. Cember, 1958: Method of tracing ground-level distribution of stack gas emission. J. Air Poll. Control Assoc., 8, 262-265.

Hay, J. S., and F. Pasquill, 1957 : Diffusion from a fixed source at a height of a few hundred feet in the atmosphere. $J$. Fluid Mech., 2, 299-310.
Hilst, G. R., 1957: The dispersion of stack gases in stable atmospheres. J. Air Poll. Control Assoc., 7, 205-210.

Leighton, P. A., 1955: The Stanford fluorescent particle tracer technique. Department of Chemistry, Stanford University. [Defense Documentation Center, AD 91 194.]

- 1960 : Quarterly Report 448-4. Contract DA 48-007-CML448. [Defense Documentation Center, AD 248 607.]

- - W. A. Perkins, S. W. Grinnell and F. X. Webster, 1947: Bimonthly Report No. 11. Contract W-18-035-CWS-1256. [Stanford University.]

Perkins, W. A., P. A. Leighton, S. W. Grinnell and F. X. Webster, 1952: Proc. Second Natl. Air Poll. Symposium. Pasadena, Calif., p. 42.

Robinson, E., J. A. McLeod and C. E. Lapple, 1959: A meteorological tracer technique using uranine dye. $J$. Appl. Meteor., 16, 63-67.

Rosin, P., and E. Rammler, 1933: The laws governing the fineness of powdered coal. J. Inst. Fuel, 7, 29-36.

Vaughan, L. M., and W. A. Perkins, 1961: The washout of aerosol particles and gases by rain. Technical Report No. 88, Aerosol Laboratory, Stanford University. [Defense Documentation Center, AD 249 877.]

Webster, F. X., 1963 : Collection efficiency of the Rotorod sampler. Technical Report No. 98, Metronics Associates, Inc., Palo Alto, Calif. [Defense Documentation Center, AD 418 597.] 